\title{
Construção de atribuições em saúde bucal para agentes comunitários de saúde através da técnica Delphi
}

\author{
Building oral health assignments for community health workers \\ through the Delphi technique
}

Alex Luís Sass (https:// orcid.org/ 0000-0001-9202-5392) ${ }^{1}$

Fernando Neves Hugo (https:// orcid.org/ 0000-0003-2222-7719) ${ }^{2}$

Aline Hübner da Silva (https://orcid.org/ 0000-0002-6327-6018) ${ }^{1}$

Daniela Jorge Corralo (https://orcid.org/ 0000-0003-3034-1730) ${ }^{1}$

Micheline Sandini Trentin (https://orcid.org/ 0000-0001-5040-3578) ${ }^{3}$

\footnotetext{
${ }^{1}$ Clínica Odontológica, Faculdade de Odontologia, Universidade de Passo Fundo. Av. Brasil Leste 285, São José. 99052-900 Passo Fundo RS Brasil.

alexsass@gmail.com ${ }^{2}$ Faculdade de Odontologia, Universidade Federal do Rio Grande do Sul. Porto Alegre RS Brasil.

${ }^{3}$ Periodontia, Faculdade de Odontologia, Universidade de Passo Fundo. Passo Fundo RS Brasil.
}

\begin{abstract}
The literature does not clearly define the assignments of Community Health Workers (CHW) in the field of oral health. This study aimed to redefine the main assignments of $\mathrm{CHW}$ regarding their work processes in oral health in basic health care. A theoretical-logical model based on an official publication from the Brazilian Ministry of Health, with six dimensions of work, was used. The model was built based on the assignments of CHW in Dentistry and sent to 30 experts chosen intentionally for the consensual study, using the Delphi technique. The matrix presented the following dimensions: registration of families, mapping the coverage area, home visits, work with community health education, participation in the community, and intersectoral work. These dimensions were detailed with sub-dimensions and measurable criteria. After the study participants analyzed the dimensions, two criteria were excluded. Fourteen experts concluded the study. The final matrix showed the need for $\mathrm{CHW}$ to be trained in several oral health topics. This study provides an objective framework of the work process of CHW in oral health and shows their ability to perform oral health promotion, surveillance, prevention, and education actions.
\end{abstract}

Key words Community Health Worker, Oral health, Family Health Strategy
Resumo As atribuições dos Agentes Comunitários em Saúde (ACS) na área da saúde bucal não estão claramente especificadas na literatura. Este estudo objetivou redefinir as principais atribuições dos ACS em relação aos processos de trabalho em saúde bucal na atenção básica à saúde. Utilizou-se um modelo teórico lógico baseado em publicação oficial do Ministério da Saúde, com seis dimensões de trabalho. O modelo construído sobre as atribuições dos ACS na Odontologia foi enviado a trinta "experts" escolhidos de forma intencional para o estudo consensual através da técnica Delphi. A matriz apresentou como dimensões: cadastramento das famílias, mapeamento da área de atuação, visita domiciliar, trabalhando educação em saúde na comunidade, participação na comunidade e atuação intersetorial. O detalhamento dessas dimensões foi realizado com subdimensões e critérios mensuráveis. Depois de analisadas as dimensões pelos participantes do estudo, dois critérios foram excluidos. Quatorze experts realizaram o estudo por completo. A matriz final demonstrou a necessidade do ACS estar capacitado em diversos tópicos de saúde bucal. Este estudo fornece uma imagem-objetivo do processo de trabalho do ACS em saúde bucal e demonstra a capacidade do mesmo de realizar atividades de promoção, vigilância, prevenção e educação em saúde bucal.

Palavras-chave Agente Comunitário de Saúde, Saúde bucal, Estratégia Saúde da Família 


\section{Introdução}

No ano de 2002, foi criada a profissão de Agente Comunitário de Saúde (ACS) ${ }^{1,2}$. Em 5 de janeiro de 2018, a Lei $n^{\circ} 11.350 / 2006^{3}$, que regulamenta as atividades de Agente Comunitário de Saúde e Agente de Combate as Endemias (ACE) sofreu nova alteração (Lei no 13.595$)^{4}$, dispondo sobre a reformulação das atribuições, a jornada e as condições de trabalho, o grau de formação profissional, os cursos de formação técnica e continuada e sobre a indenização de transporte dos profissionais ACS e ACE ${ }^{4}$.

De acordo com o Guia Prático do Agente Comunitário de Saúde ${ }^{5}$, as ações em saúde bucal são divididas em três eixos principais de atenção: crianças, adolescentes e adultos. O documento sobre o trabalho do Agente Comunitário de Saú$\mathrm{de}^{6}$ detalha as ações do ACS em seis dimensões de trabalho: o cadastramento das famílias, o mapeamento da área de atuação, a visita domiciliar, trabalhando educação em saúde na comunidade, a participação na comunidade e a atuação intersetorial.

Atualmente, não existe publicação oficial do Ministério da Saúde claramente relacionada às ações do ACS em saúde bucal. O trabalho deste profissional está mais caracterizado pela aproximação com a área médica e de enfermagem, demonstrando certo distanciamento da Odontologia ${ }^{6}$. A interação com profissionais de outras áreas da saúde permite a análise do indivíduo como um todo e atenta ao contexto sócio-econômico-cultural no qual ele está inserido ${ }^{7}$.

Para tanto, é necessário que novas estratégias de aprendizagem sejam empregadas para a formação do ACS no contexto da Estratégia de Saúde da Família (ESF), para que qualifique seu processo de trabalho com educação continuada. Observa-se ainda, que o conhecimento do processo saúde/doença bucal dos ACS vinculados à ESF com Equipes de Saúde Bucal (ESB) são mais efetivos ${ }^{8}$. As dificuldades encontradas no trabalho do ACS na Odontologia demonstraram a necessidade de reavaliar quais as ações em saúde bucal o mesmo pode desenvolver nas Unidades Básicas de Saúde (UBS) e ESF, além de definir os critérios e indicadores para avaliação dos mesmos.

As dificuldades dos Agentes Comunitários em Saúde podem resultar do processo de qualificação desestruturado e fragmentado, e na maioria das vezes insuficiente para a atuação do mesmo na área da saúde. Na saúde bucal, de acordo com Gouvêa et al. ${ }^{8}$, os ACS realizam pou- cas atividades de educação em saúde bucal ou as realizam de forma esporádica, justificando o fato de não terem sido capacitados para isso. $\mathrm{O}$ cirurgião-dentista poderia atuar como um tutor orientando essas ações.

Dessa forma, a construção de atribuições e indicadores é fundamental para avaliação da efetividade das ações, resolução de problemas de ordem geral e bucal, tomadas de decisões e respostas do pensamento populacional e/ou intelectual ${ }^{9}$, desenvolvendo assim, ações de educação continuada em saúde para esses trabalhadores.

$\mathrm{O}$ objetivo desta pesquisa foi redefinir as atribuições dos ACS em relação aos processos de trabalho em saúde bucal nas UBS e ESF utilizando a técnica Delphi ${ }^{10,11}$ direcionada para gestores atuantes na coordenação de saúde bucal nacional, estadual e/ou municipal, pesquisadores e/ou professores universitários com pós-graduação na área de saúde bucal coletiva e cirurgiões-dentistas que atuam na rede de atenção básica na ESB.

\section{Materiais e métodos}

O estudo foi aprovado pelo Comitê de Ética em Pesquisa da Universidade de Passo Fundo, Rio Grande do Sul. Todos os participantes que concordaram em participar do estudo se responsabilizaram em responder aos questionários, mas tiveram a liberdade de desistir do estudo nas etapas seguintes.

\section{Seleção dos participantes}

A seleção dos participantes deste estudo foi realizada pela equipe coordenadora de forma intencional com indivíduos externos à entidade envolvida (Profissionais da área de Saúde Coletiva atuando na área há mais de 5 anos e "conhecidos" dos coordenadores da pesquisa). Trinta profissionais foram convidados para participar do estudo, provenientes de diferentes regiões do Brasil (Sul, Sudeste, Norte, Nordeste), número considerado suficiente para gerar informações relevantes ${ }^{12,13}$. Foram convidados via e-mail através do Formulário FormSus ${ }^{\circledR}$ (http://formsus.datasus.gov.br/ site/default.php ${ }^{14}$ dez gestores atuantes na coordenação de saúde bucal nacional, estadual e/ou municipal; dez professores-pesquisadores universitários com pós-graduação na área de saúde bucal coletiva e dez cirurgiões-dentistas que atuavam na rede de atenção básica em ESB há pelo menos 5 anos. 


\section{Construção do Questionário}

A técnica Delphi ${ }^{9-13}$ foi utilizada como ferramenta da pesquisa, consistindo das seguintes etapas: revisão de literatura e um painel de três fases.

Um modelo teórico-lógico foi construído, constituído por uma matriz inicial dividida nas seis dimensões do processo de trabalho do ACS, teoricamente embasada em publicação oficial ${ }^{6}$ "quadro 1 ACS".

A equipe de coordenação, composta por três pesquisadores, elaborou um questionário com respostas individuais, quantitativas, complementadas por justificativas e informações qualitati$\operatorname{vas}^{13}$.

A matriz inicial, seguida do questionário foi apresentada aos participantes. O período da coleta de dados foi entre novembro de 2013 a julho de 2014.

O questionário foi disponibilizado online através da plataforma FormSus ${ }^{\circledR 14}$, serviço fornecido pelo Departamento de Informática do SUS (DATASUS) para criação de formulários online, sendo de uso público e com normas bem definidas. Através da inserção do formulário na plataforma FormSus ${ }^{\circledR 14}$, o mesmo envia login e senha aos participantes através de e-mail. Os especialistas que acessaram a plataforma online foram orientados com relação ao preenchimento do formulário, concordaram em participar do estudo com prazo de resposta de até quinze dias. Os mesmos foram mantidos anônimos em todas as etapas do estudo.

$\mathrm{Na}$ totalidade do processo do estudo foram realizadas três rodadas para análise da Matriz, e formulação das sugestões após cada rodada. Os dados foram sumarizados em planilhas do Excel e o resultado final apresentado aos participantes através de e-mail.

\section{Primeira fase: Modelo Téorico Inicial}

$\mathrm{Na}$ primeira fase do estudo (modelo teórico inicial), os participantes responderam ao questionário, atribuindo notas de 0 a 10 para cada uma das trinta e quatro questões fechadas e seis abertas (para indicar outros aspectos que consideraria relevante para a dimensão em questão), referentes ao processo de trabalho do ACS. Para cada uma das questões foi apresentada uma Escala Visual Analógica (EVA) de 0-10. O Quadro 1 apresenta as dimensões sugeridas pela publicação "O trabalho do Agente Comunitário de Saúde, 2009"6.

\section{Segunda fase: Estudo de Consenso}

A partir do retorno da análise das atribuições dos ACS pelos "experts", os critérios com consenso foram mantidos e exportados para a matriz lógica final. Os comentários obtidos a partir das questões discursivas deram origem a novas perguntas formuladas pela equipe organizadora para uma segunda rodada do processo.

\section{Terceira fase}

A terceira rodada definiu o peso das dimensões e dos critérios estabelecidos. A atribuição dos pesos foi realizada segundo escala crescente de 1 a 3, com o objetivo de propor uma nova matriz para as atribuições do ACS na saúde bucal.

\section{Análise estatística}

As duas primeiras rodadas definiram os critérios como importantes e consensuais quando atingiram média $\geq 7$ e desvio padrão $<3^{15}$. Assim, critérios com consenso foram exportados para a matriz teórica lógica final e os critérios sem consenso foram excluídos. Os comentários nas questões discursivas deram origem a novas perguntas formuladas pela equipe organizadora em uma segunda rodada.

A terceira e última rodada definiu os pesos das dimensões e critérios, segundo a mediana. Os pesos dos critérios sofreram ponderação ${ }^{16}$. A ponderação se deu pelo valor da mediana dividido pelo total de pontuação na dimensão, o resultado multiplicado por 100 gerou o valor atribuído ao critério.

\section{Resultados}

Foram convidados 30 profissionais, dos quais $19(63,3 \%)$ aceitaram participar do estudo. O percurso metodológico deste trabalho definiu o tempo de quinze dias para acesso à plataforma FormSus ${ }^{\circledR 14}$ e resposta ao formulário. O não acesso dos convidados neste período foi considerado como convite não aceito. $\mathrm{Na}$ segunda fase, 18 $(94,7 \%)$ participantes responderam e na terceira houve 14 respondentes $(68,4 \%)$ (Figura 1$)$.

\section{Primeira fase do estudo Delphi}

Na primeira fase do estudo, dos trinta e quatro critérios, 32 obtiveram média $\geq 7$ e desvio padrão $<3$. Os critérios 31 e 32 foram excluídos por não atingirem a média $\geq 7$ e desvio padrão $<3$ os mesmos se referiam a dimensão de "atuação in- 
Quadro 1. Dimensões sugeridas pela publicação “O trabalho do Agente Comunitário de Saúde, 2009”" para a atuação do Agente Comunitário de Saúde (ACS) área da saúde bucal.

\begin{tabular}{|c|c|}
\hline \multicolumn{2}{|r|}{ Cadastramento das Famílias } \\
\hline 1 & $\begin{array}{l}\text { O ACS, ao realizar cadastramento das famílias, deve acessar informações que contribuam na identificação } \\
\text { dos grupos de ações de promoção, proteção e recuperação em saúde bucal. }\end{array}$ \\
\hline 2 & $\begin{array}{l}\text { O ACS pode contribuir na identificação de grupos de ações em saúde bucal através da utilização de } \\
\text { indicadores de agravos em saúde bucal. }\end{array}$ \\
\hline 3 & $\begin{array}{l}\text { O ACS deve identificar fatores de risco ou de proteção simultâneos tanto para doenças da cavidade bucal } \\
\text { quanto para outros agravos (diabetes, hipertensão, obesidade, câncer e pessoas com deficiência). }\end{array}$ \\
\hline 4 & $\begin{array}{l}\text { O ACS deve identificar as principais situações de risco, tais como: falta de acesso a produtos de higiene } \\
\text { bucal, consumo excessivo e frequente de açúcar, e a frequência das consultas odontológicas das famílias. }\end{array}$ \\
\hline 5 & $\begin{array}{l}\text { O câncer de boca está entre as principais causas de óbito por neoplasias. O mesmo pode ser prevenido } \\
\text { de forma simples, dando ênfase à promoção da saúde, ao aumento do acesso aos serviços de saúde e } \\
\text { diagnóstico precoce. O ACS deve identificar situações de risco ao câncer de boca nas famílias como: } \\
\text { tabagismo, etilismo e exposição à radiação solar. }\end{array}$ \\
\hline 6 & $\begin{array}{l}\text { A Atenção programada é caracterizada por pessoas cadastradas na área que compõem o grupo priorizado } \\
\text { para a Atenção na Unidade de Saúde e que necessitam de atendimento continuado. Cabe ao ACS, em } \\
\text { conjunto com a ESB e comunidade, identificar esses grupos. }\end{array}$ \\
\hline 7 & $\begin{array}{l}\text { Cabe ao ACS identificar pessoas com necessidades especiais, as quais devem ser caracterizadas como grupo } \\
\text { de atenção odontológica priorizada. }\end{array}$ \\
\hline 8 & $\begin{array}{l}\text { Os grupos de risco em saúde bucal identificados pelo ACS, baseiam-se em critérios de frequência, risco e } \\
\text { vulnerabilidade a doenças, conforme necessidades da população local. }\end{array}$ \\
\hline \multicolumn{2}{|r|}{ Mapeamento da Área de Atuação } \\
\hline 9 & $\begin{array}{l}\text { O mapeamento da área de atuação do ACS deve contribuir no diagnóstico e planejamento das ações da } \\
\text { ESB, o mesmo deve trazer informações pertinentes à saúde bucal, incluindo: acesso à água encanada, } \\
\text { consultórios odontológicos privados e infraestruturas de serviços disponíveis. }\end{array}$ \\
\hline 10 & $\begin{array}{l}\text { No mapeamento em saúde bucal, as informações devem ser identificadas no cadastro das famílias com } \\
\text { relação a grupos e situações de risco em saúde bucal. }\end{array}$ \\
\hline 11 & Neste mapa, também devem estar identificados grupos de atenção odontológica priorizada. \\
\hline 12 & A ESB deve contribuir com o ACS na formulação desse mapeamento em saúde bucal. \\
\hline 13 & $\begin{array}{l}\text { O mapeamento deve possibilitar à ESB e ACS avaliarem situações de risco interdisciplinares, que } \\
\text { relacionem saúde bucal com outros problemas de saúde. }\end{array}$ \\
\hline
\end{tabular}

tersetorial". Estes critérios abordaram a responsabilidade do ACS em identificar setores e atores fora da área de saúde, que possam contribuir no planejamento de ações em saúde bucal. A falta de concordância nestes fatores, através da análise dos comentários mostrou que os participantes julgam que essa função cabe a ESF e não somente ao ACS.

Nas questões abertas, sete sugestões ou comentários dos participantes deram origem a cinco novos critérios na segunda fase.

A devolutiva de cada fase do questionário com os resultados e comentários foi enviada para todos os participantes após cada rodada, informando resultados de média e desvio padrão, bem como justificativas de exclusão dos critérios (Quadro 2).

\section{Segunda fase do estudo Delphi}

Nesta fase, cinco questões foram criadas como resultado das questões abertas da primeira fase, conforme descrito acima, nas dimensões abordadas.

Houve consenso nos cinco critérios apresentados anteriormente. Nas questões abertas houve 10 comentários. A equipe coordenadora justificou na totalidade esses comentários por não acrescentarem abordagens no âmbito de atribuições em saúde bucal do ACS. Somente um critério foi realocado, o critério 9, pois foi considerado mais relacionado com a dimensão "Trabalhando educação em saúde na Comunidade”, tendo saído da dimensão "Participação na Comunidade". 
Quadro 1. Dimensões sugeridas pela publicação "O trabalho do Agente Comunitário de Saúde, 2009”6 para a atuação do Agente Comunitário de Saúde (ACS) área da saúde bucal.

\section{Visita Domiciliar}

14 Durante a visita domiciliar, o ACS deve obedecer ao planejamento desenvolvido em conjunto com a ESB, pautado nas necessidades de cada família. Novas situações ou grupos de risco podem ser identificados durante a visita, sendo necessário novo planejamento.

15 O ACS, durante a visita domiciliar, deve estimular as práticas de autocuidado dos pacientes, de caráter preventivo e promoção em saúde bucal.

16 O ACS, durante visita domiciliar, deve identificar situações que exijam medidas de diagnóstico, tratamento e reabilitação, e repassá-las à ESB.

17 As visitas domiciliares em saúde bucal devem ser planejadas em conjunto com a ESB.

18 Procedimentos educativo-preventivos podem ser realizados nos domićlios pelo ACS, de acordo com planejamento estabelecido em conjunto com a ESB.

19 O ACS deve priorizar as visitas domiciliares a grupos e situações de risco em saúde bucal, conforme diagnóstico e planejamento estabelecidos em conjunto com a ESB.

\section{Trabalhando Educação em Saúde na Comunidade}

20 O conteúdo que o ACS pode abordar em ações educativas inclui: doenças bucais, diagnóstico e prevenção; autocuidado, higiene bucal, escovação com dentifrício fluoretado e uso de fio dental, orientações sobre dieta, autoexame de boca, cuidados após traumatismo dentário, uso de álcool, fumo e drogas.

21 As ações do ACS em atividades educativas devem ser planejadas em conjunto com a ESB, definindo ações por ciclo, condição de vida e fatores de risco comuns para várias doenças.

22 Atividades de educação em saúde bucal realizadas pelo ACS devem obedecer a metodologias e didáticas definidas em conjunto com a ESB.

23 Cabe ao ACS durante atividades de educação em saúde, explicar o funcionamento da Atenção em Saúde Bucal prestada pelo Município, incluindo informações sobre: marcação de consultas, procedimentos realizados, modalidade de atenção e fluxo de atenção secundária e terciária.

24 O ACS deve apoiar e desenvolver atividades referentes à saúde bucal com os demais membros da Equipe de Saúde da Família, integrando ações de saúde de forma interdisciplinar.

25 As atividades de educação em saúde bucal realizadas pelo ACS não devem sobrepor-se às atividades realizadas pela ESB, devendo ter caráter complementar de vigilância e promoção de saúde bucal, conforme definido no plano de ação.

\section{Participação da Comunidade}

26 Cabe ao ACS a troca de conhecimentos com a comunidade de sua microárea, auxiliando a ESB no desenvolvimento de estratégias para enfrentamento dos problemas existentes.

27 A troca de conhecimentos com a comunidade por parte do ACS pode ajudar a ESB na identificação das dificuldades enfrentadas pela população no acesso ao Serviço de saúde bucal da UBS.

28 O ACS deve identificar espaços sociais em sua microárea, contribuindo no planejamento em saúde bucal da Equipe de Saúde.

29 O ACS deve verificar na comunidade dificuldades encontradas relacionadas à saúde bucal e estratégias sugeridas para o enfrentamento dos problemas.

30 Durante o processo de trabalho, o ACS deve conhecer na comunidade as condições de vida, hábitos e providências para resolver situações-problema e evitar enfermidades em saúde bucal.

Atuação Intersetorial

31 Cabe ao ACS identificar setores e atores fora da área da saúde que possam contribuir no planejamento de ações em saúde bucal.

32 A identificação desses setores por parte do ACS deve-se basear em critérios de risco, possibilidade de atuação e recursos disponíveis para atuação em saúde bucal.

33 O ACS deve reconhecer condicionalidades que interferem na saúde bucal do indivíduo como participação em programas sociais do Governo, como o Bolsa Família, ou de qualquer outro programa similar de transferência de renda.

34 O ACS, em conjunto com a ESB, deve participar do planejamento das ações do Programa de Saúde na Escola (PSE), auxiliando na identificação de critérios de risco, recursos disponíveis e realização de procedimentos coletivos. 


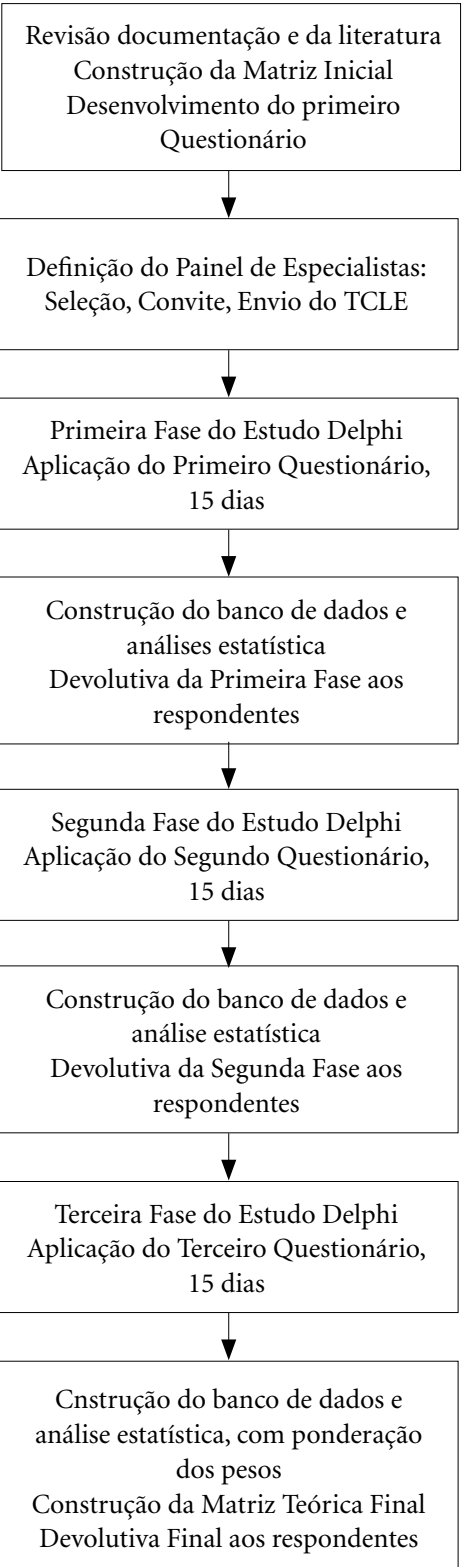

Figura 1. Fluxograma do estudo.

\section{Terceira fase do estudo Delphi}

A terceira e última fase do estudo definiu o peso das dimensões de trabalho e critérios do ACS em saúde bucal. Foi apresentada a matriz final com 32 critérios e 6 dimensões do processo de trabalho em saúde bucal do ACS, as quais po- dem ser observadas no Quadro 3. A ponderação dos pesos e valores atribuídos em cada dimensão estão descritos na Tabela 1.

\section{Discussão}

O fortalecimento da Atenção Básica (AB) é a principal premissa do modelo de atenção à saúde implementado no Brasil ${ }^{17}$ e tem sido revisado, conforme evidenciado pela Política Nacional de Atenção Básica (PNAB), Portaria no 2.436, de 21 de setembro de $2017^{18}$. Para a consolidação dos princípios e diretrizes propostos pela $\mathrm{PNAB}^{18}$, é imprescindível o respeito à cultura do território e saberes populares das pessoas que vivenciam seu processo saúde-doença ${ }^{17}$. Neste contexto, o ACS deve ser considerado um componente essencial da equipe da ESF, pois desempenha um papel mediador entre os saberes técnicos e populares, contribuindo para a proposta de qualificação da atenção à saúde, na busca de uma atenção integral ao indivíduo, na qual a saúde bucal não pode ser dissociada.

O presente estudo desenvolveu um consenso com relação às atribuições em saúde bucal para o ACS em seis dimensões teóricas extraídas de publicação oficial do Ministério da Saúde ${ }^{6}$. A matriz final foi composta de 32 critérios organizados segundo as dimensões do processo de trabalho do $\mathrm{ACS}^{6}$ e expressa opinião qualificada e consensual de um grupo de profissionais, gestores e professores/pesquisadores universitários com reconhecido conhecimento sobre Saúde da Família e Saúde Bucal Coletiva.

A discussão e definição de um consenso sobre as atribuições do ACS em relação Saúde Bucal permite atuarem com mais confiança na abordagem dos assuntos relacionados a odontologia. $\mathrm{O}$ ACS possui um papel único em uma equipe de saúde da família, pois convive com a realidade do bairro onde trabalha e mora, conhece os costumes da população e promove uma aproximação entre a comunidade e os profissionais da saúde, facilitando o desenvolvimento de ações em benéfico da melhoria da qualidade de vida dos usuários, conforme reforçam Pereira e Limongi ${ }^{19}$.

Esse estudo de consenso apresenta-se com um caráter de ineditismo, considerando que há poucos estudos atuais sobre o assunto. A atuação do ACS precisa obedecer a critérios da $\mathrm{PNAB}^{18}$ contribuindo para o trabalho interdisciplinar da ESF. Reconhece-se, nessa dinâmica, a importância do agente comunitário de saúde ser um trabalhador que faz parte da equipe de saúde da 
Quadro 2. Sugestões de modificação pelos Experts do estudo na primeira e segunda fase do estudo de Delphi.

\begin{tabular}{|c|c|c|}
\hline \begin{tabular}{|c|} 
Dimensões do \\
processo de \\
trabalho do ACS \\
\end{tabular} & Primeira fase & Segunda fase \\
\hline $\begin{array}{l}\text { Cadastramento } \\
\text { das famílias }\end{array}$ & Sem sugestões & Não houve comentários nesta dimensão \\
\hline $\begin{array}{l}\text { Mapeamento da } \\
\text { área de atuação }\end{array}$ & $\begin{array}{l}\text { 1- Localização de espaços sociais (escolas, } \\
\text { creches, grupos religiosos, associações de } \\
\text { moradores) para potencializar ações ou } \\
\text { identificar locais de risco. } \\
\text { 2- Especificar as famílias que possuem } \\
\text { indivíduos acamados/impossibilitados de } \\
\text { irem a UBS. }\end{array}$ & $\begin{array}{l}\text { 1- Devem ser identificados locais de difícil } \\
\text { acessibilidade, como morros ou encostas e/ } \\
\text { ou locais de violência urbana; áreas com } \\
\text { populações quilombolas, acampados, } \\
\text { ribeirinhas e/ou outras contidas na } \\
\text { modalidade da equipe } 1 \text { de Saúde da Família. } \\
\text { 2- O fato de serem acamados ou com } \\
\text { necessidades especiais não os torna } \\
\text { prioritários. Eles devem ser identificados para } \\
\text { que o serviço os encontre. }\end{array}$ \\
\hline Visita Domiciliar & $\begin{array}{l}\text { 3- Inclusão de tópico sobre a criação } \\
\text { de vínculo na visita domiciliar do ACS, } \\
\text { conforme atributos da ESB. }\end{array}$ & Não houve comentários nesta dimensão \\
\hline $\begin{array}{l}\text { Trabalhando } \\
\text { Educação } \\
\text { em Saúde na } \\
\text { Comunidade }\end{array}$ & $\begin{array}{l}\text { 4- Atividades devem dialogar com os } \\
\text { costumes e cultura da população adstrita. } \\
\text { 5- O ACS tem uma postura educativa } \\
\text { prescritiva/normativa, limitada ao que é } \\
\text { "certo ou errado" para os usuários, sem } \\
\text { considerar o contexto da replicação de } \\
\text { cartilhas e manuais do ministério. }\end{array}$ & $\begin{array}{l}\text { 3- Importante considerar o conhecimento } \\
\text { e experiência dos participantes permitindo } \\
\text { a troca de ideias. Isso estimula a pessoa a } \\
\text { construir um processo decisório autônomo e } \\
\text { centrado em seus interesses. } \\
\text { 4- Preocupa estarmos lidando com várias } \\
\text { habilidades e competências para a ação do ACS } \\
\text { desconsiderando completamente a ESF. Fica } \\
\text { a impressão que teremos cronograma para as } \\
\text { tarefas, uma hora saúde e outra saúde bucal. } \\
\text { 5- O diálogo dos costumes e cultura não deve } \\
\text { ser atribuição só do ACS, mas de toda a equipe. }\end{array}$ \\
\hline $\begin{array}{l}\text { Participação na } \\
\text { Comunidade }\end{array}$ & $\begin{array}{l}\text { 6- Identificação e composição do plano } \\
\text { terapêutico considerando as Práticas } \\
\text { Integrativas e Complementares do SUS } \\
(\text { PICS })^{18} \text {. }\end{array}$ & $\begin{array}{l}\text { - As questões } 8 \text { e } 9 \text { não estão alinhadas à } \\
\text { premissa da participação na comunidade, } \\
\text { estaria mais ligada ao atributo: práticas } \\
\text { do cuidado em saúde; considerando-se } \\
\text { impertinente para este componente. }\end{array}$ \\
\hline $\begin{array}{l}\text { Atuação } \\
\text { Intersetorial }\end{array}$ & $\begin{array}{l}\text { - Exclusão dos itens } 31 \text { e } 32 \text { por não } \\
\text { atingirem média e desvio padrão. } \\
\text {-"Também" cabe ao ACS no item } 31 \\
\text { identificar setores e atores fora da Área } \\
\text { da Saúde, que possam contribuir no } \\
\text { planejamento de ações em saúde bucal. } \\
\text { - o Tópico } 32 \text { depende de conhecimento } \\
\text { prévio de fatores de risco, de sua } \\
\text { interpretação, o que julgo ser um pouco } \\
\text { distante da realidade dos ACS, como } \\
\text { mencionado nas observações do primeiro } \\
\text { campo de preenchimento sobre cadastro das } \\
\text { famílias } \\
\text { - Os ítens } 31 \text { e } 32 \text { devem ser realizados pela } \\
\text { equipe da ESF. }\end{array}$ & - Não houve comentários nesta dimensão \\
\hline
\end{tabular}

comunidade onde vive, o que permite a ele uma forte relação entre o seu trabalho e a sua vida social $^{20}$. No entanto, o mesmo deve constantemente obter habilidades e capacidades para o aperfeiço- amento da prática profissional e promover melhorias das condições de saúde da população no âmbito das necessidades básicas ${ }^{18}$, sendo a saúde bucal um aspecto de enorme relevância. 
Quadro 3. Matriz final sugerida após a aplicação da Técnica Delphi para a redefinição da atuação do Agente Comunitário de Saúde (ACS) área da saúde bucal.

\begin{tabular}{|c|c|}
\hline \multicolumn{2}{|r|}{ Cadastramento das Famílias } \\
\hline 1 & Identificação de grupos de ações de promoção, proteção e recuperação em Saúde Bucal. \\
\hline 2 & $\begin{array}{l}\text { Identificação de fatores de risco de proteção simultâneos para doenças da cavidade bucal e outros agravos } \\
\text { (diabete, hipertensão, obesidade, trauma, câncer e portadores de deficiência). }\end{array}$ \\
\hline 3 & $\begin{array}{l}\text { Identificação das principais situações de risco como: falta de acesso a produtos de higiene bucal, consumo } \\
\text { excessivo e frequente de açúcar e frequência de consultas odontológicas das famílias. }\end{array}$ \\
\hline 4 & $\begin{array}{l}\text { Identificação de risco de câncer de boca nas famílias, incluindo situações como: tabagismo, etilismo e } \\
\text { exposição à radiação solar. }\end{array}$ \\
\hline 5 & $\begin{array}{l}\text { Identificação de pessoas com necessidades especiais, caracterizadas como de Atenção odontológica } \\
\text { priorizada. }\end{array}$ \\
\hline 6 & $\begin{array}{l}\text { Os grupos de risco identificados pelo ACS baseiam-se em critérios de frequência, risco e vulnerabilidade a } \\
\text { doenças, conforme necessidades da população local identificadas em diagnóstico realizado pela ESB. }\end{array}$ \\
\hline \multicolumn{2}{|r|}{ Mapeamento da Área de Atuação } \\
\hline 7 & $\begin{array}{l}\text { Trazer informações pertinentes à saúde bucal, incluindo: acesso à água encanada, consultórios } \\
\text { odontológicos privados e outras infraestruturas disponíveis que possam influenciar a Saúde Bucal }\end{array}$ \\
\hline 8 & $\begin{array}{l}\text { Devem estar identificadas as informações obtidas no cadastro das famílias com relação a grupos e } \\
\text { situações de risco em saúde bucal. }\end{array}$ \\
\hline 9 & Identificar grupos de atenção odontológica priorizada, conforme os dados obtidos no cadastramento. \\
\hline 10 & A ESB deve contribuir com o ACS na formulação desse mapeamento em saúde bucal \\
\hline 11 & $\begin{array}{l}\text { Possibilitar à ESB e ACS avaliarem situações de risco interdisciplinares que relacionem saúde bucal com } \\
\text { outros problemas de saúde. }\end{array}$ \\
\hline 12 & $\begin{array}{l}\text { O ACS deve obter a localização ou mapeamento dos espaços sociais organizados (escolas, creches, grupos } \\
\text { religiosos, associações de moradores, etc.) para planejar ações em saúde bucal em conjunto com a ESB. }\end{array}$ \\
\hline 13 & $\begin{array}{l}\text { Indivíduos acamados, impossibilitados de irem à USB e pacientes com necessidades especiais devem ser } \\
\text { caracterizados como Grupo de Atenção Odontológica Priorizada. }\end{array}$ \\
\hline \multicolumn{2}{|r|}{ Visita Domiciliar } \\
\hline 14 & $\begin{array}{l}\text { Deve obedecer ao planejamento desenvolvido em conjunto com a ESB, pautado na identificação das } \\
\text { necessidades de cada família. Novas situações, pessoas e famílias em risco podem ser identificadas durante } \\
\text { a visita, sendo necessário novo planejamento. }\end{array}$ \\
\hline 15 & Deve estimular práticas de autocuidado com caráter preventivo e de promoção da Saúde bucal. \\
\hline 16 & Deve identificar situações de diagnóstico, tratamento e reabilitação e repassá-las à ESB. \\
\hline 17 & $\begin{array}{l}\text { Deve incluir procedimentos coletivos e educativo-preventivos que possam ser realizados nos domicílios } \\
\text { pelo ACS, de acordo com planejamento estabelecido em conjunto com a ESB. }\end{array}$ \\
\hline 18 & $\begin{array}{l}\text { Priorizar visitas domiciliares a grupos e situações de risco em saúde bucal, conforme diagnóstico e } \\
\text { planejamento estabelecidos em conjunto com a ESB. }\end{array}$ \\
\hline 19 & $\begin{array}{l}\text { Deve ser indutora de tecnologias leves, criando processos de acolhimento e atenção em saúde bucal, com } \\
\text { o objetivo de identificar as necessidades dos usuários e melhor forma de resolvê-las. }\end{array}$ \\
\hline \multicolumn{2}{|r|}{ Trabalhando Educação em Saúde na Comunidade } \\
\hline 20 & $\begin{array}{l}\text { O conteúdo que o ACS pode abordar em ações educativas deve ser: doenças bucais, sua manifestação e } \\
\text { prevenção, importância do autocuidado com a higiene bucal, escovação com dentifrício fluoretado e uso } \\
\text { de fio dental, cuidados para evitar fluorose, orientações sobre dieta, autoexame de boca, cuidados pós- } \\
\text { traumatismos dentários, prevenção ao sol sem proteção e prevenção ao álcool, fumo e drogas. }\end{array}$ \\
\hline 21 & $\begin{array}{l}\text { As ações devem ser planejadas em conjunto com a ESB, definindo ações por ciclo, condições de vida e } \\
\text { fatores de risco comuns para várias doenças. }\end{array}$ \\
\hline 22 & As ações devem obedecer à metodologia e didática definidas em conjunto com a ESB. \\
\hline 23 & $\begin{array}{l}\text { As ações devem apoiar e desenvolver atividades referentes à saúde bucal com os demais membros da ESF, } \\
\text { buscando aproximar e integrar ações de saúde de forma interdisciplinar. }\end{array}$ \\
\hline 24 & $\begin{array}{l}\text { As ações não devem sobrepor atividades realizadas pela ESB, devendo ter caráter complementar de } \\
\text { vigilância e promoção de saúde bucal, conforme definido no plano de ação. }\end{array}$ \\
\hline 25 & $\begin{array}{l}\text { A educação em saúde bucal realizada pelo ACS deve dialogar com costumes e cultura da população } \\
\text { adstrita. }\end{array}$ \\
\hline 26 & $\begin{array}{l}\text { O ACS deve conhecer na comunidade, as condições de vida, hábitos e providências que essa toma para } \\
\text { resolver os problemas e o que a mesma faz para evitar enfermidades em saúde bucal. }\end{array}$ \\
\hline
\end{tabular}


Quadro 3. Matriz final sugerida após a aplicação da Técnica Delphi para a redefinição da atuação do Agente Comunitário de Saúde (ACS) área da saúde bucal.

\begin{tabular}{|l|l|}
\hline \multicolumn{2}{|c|}{ Participação da Comunidade } \\
\hline 27 & $\begin{array}{l}\text { Cabe ao ACS buscar a troca de conhecimentos com a comunidade de sua microárea, auxiliando a ESB no } \\
\text { desenvolvimento de estratégias para enfrentamento dos problemas existentes. }\end{array}$ \\
\hline 28 & $\begin{array}{l}\text { A troca de conhecimentos com a comunidade pelo ACS pode ajudar a ESB na identificação de } \\
\text { dificuldades encontradas pela população no acesso ao Serviço de Saúde Bucal da UBS. }\end{array}$ \\
\hline 29 & $\begin{array}{l}\text { O ACS deve identificar espaços sociais em sua microárea que possam contribuir no planejamento em } \\
\text { Saúde bucal da Equipe de Saúde. }\end{array}$ \\
\hline 30 & $\begin{array}{l}\text { O ACS deve verificar na comunidade dificuldades encontradas relacionadas à saúde bucal e estratégias } \\
\text { sugeridas para o enfrentamento dos problemas. }\end{array}$ \\
\hline \multicolumn{2}{|c|}{ Atuação Intersetorial } \\
\hline 31 & $\begin{array}{l}\text { O ACS deve reconhecer condicionalidades que interferem na saúde bucal do indivíduo, como a } \\
\text { participação em Programas Sociais do Governo, Bolsa Família, ou outros programas similares de } \\
\text { transferência de renda e enfrentamento de vulnerabilidade implantado pelo Governo Federal, estaduais } \\
\text { ou municipais. }\end{array}$ \\
\hline 32 & $\begin{array}{l}\text { O ACS, em conjunto com a ESB, deve participar do planejamento das ações da ESF, auxiliando na } \\
\text { identificação de critérios de risco, recursos disponíveis e realização de procedimentos coletivos. }\end{array}$ \\
\hline
\end{tabular}

Os critérios que se referiam à dimensão de "atuação intersetorial” foram excluídos após a análise dos especialistas, por apresentarem média inferior à 7. Esses critérios abordam a responsabilidade do ACS em identificar setores e atores fora da área de saúde, que possam contribuir no planejamento de ações em saúde bucal.

A justificativa para a exclusão reside no fato de que a própria produção oficial do Ministério da Saúde sobre o assunto estabelece que isso é competência da ESF como um todo, e não de uma categoria profissional específica ${ }^{21}$. Deve-se considerar que o ACS é um integrante da equipe com pouca qualificação, sendo de extrema relevância a capacitação desses profissionais para atuar nas áreas de competência ${ }^{22}$. Impor competências de elevada complexidade, como as ações intersetoriais podem dificultar a atuação do ACS no foco em ações que sejam efetivas a comunidade.

Conforme a PNAB pela Portaria no 2.436 , de 21 de setembro de $2017^{18}$, a Atenção Básica e a Vigilância em Saúde devem se unir para uma adequada identificação de problemas de saúde nos territórios e o planejamento de estratégias, sendo as atividades dos ACS e dos Agentes de Combate às Endemias, integradas. Na política foram divididas as atribuições comuns aos dois agentes e as específicas dos ACS, tendo como diferencial que os mesmos só realizarão a execução dos procedimentos que requeiram a capacidade técnica específica, se detiverem a respectiva formação, respeitada a autorização legal ${ }^{23}$. A capacitação dos ACS é um objetivo já previsto no Programa de
Agentes Comunitários de Saúde (PACS) ${ }^{24}$, proposto pelo Ministério da Saúde, proporcionando ao ACS oferecer cuidados à população, com grau de resolubilidade compatível com sua a função, contribuindo para a extensão da atenção à saúde na comunidade adscrita.

A pequena parcela de especialistas que participaram até a etapa final do estudo poderia ser uma limitação do estudo, uma vez que ocorreu uma desistência de aproximadamente 37\%. No entanto, de acordo com a técnica Delphi, o número de participantes foi suficiente para produzir um estudo de consenso ${ }^{10,13}$. O número ideal de participantes para a realização do consenso Delphi é variável. Enquanto Okoli e Pawlowski ${ }^{13}$ sugerem que entre 10 e 18 "experts" são suficientes para o desenvolvimento do método, Valdés e Marín ${ }^{25}$ sugerem um mínimo de 7 "experts", observando que o erro de consenso é diminuído notavelmente a cada especialista adicionado. Todavia, estudos recomendam a prudência de convidar mais membros do que os que estão previstos para o painel de "experts", pois usualmente ocorrem desistências ${ }^{10,13,25}$. Bloor et al. ${ }^{26}$ afirmaram que num grupo Delphi, mais importante do que o tamanho da amostra é o equilíbrio das participações representado pela gama de pontos de vista e conhecimentos. Ainda, não foi possível identificar os autores das respostas nesta pesquisa, embora seja um dado interessante, o FormSus ${ }^{\circledR 14}$ não permitia identificar o usuário, de forma a preservar o respondente, considerando que o estudo é de caráter sigiloso e confidencial. 
Tabela 1. Ponderação de pesos e valor atribuído na dimensão.

\begin{tabular}{lcc}
\hline \multicolumn{1}{c}{ Dimensão } & $\begin{array}{c}\text { Ponderação } \\
\text { dos critérios } \\
\text { na dimensão } \\
\text { (peso/total da } \\
\text { pontuação) }\end{array}$ & $\begin{array}{c}\text { Valor atribuído } \\
\text { (peso } \\
\text { ponderado } \\
\mathbf{1 0 0}\end{array}$ \\
\hline Cadastramento & 0,004 & 0,40 \\
das famílias & 0,009 & 0,90 \\
Mapeamento & 0,014 & 1,4 \\
da área de & 0,007 & - \\
atuação & 0,011 & 0,7 \\
Visita & 0,004 & 1,1 \\
domiciliar & 0,008 & 0,4 \\
Trabalhando & 0,012 & 0,8 \\
educação & 0,003 & 1,2 \\
em saúde na & 0,006 & 0,3 \\
comunidade & 0,010 & 0,6 \\
Participação na & & 1,0 \\
Comunidade & 0,011 & - \\
Atuação & 0,016 & 1,1 \\
intersetorial & - & 1,6 \\
\hline
\end{tabular}

Não foram propostas novas abordagens para as atribuições dos ACS na segunda fase do estudo. A questão das PICs no SUS ${ }^{27}$, na dimensão de "participação na comunidade", mostrou-se controversa, já que depende de capacitação específica e inserção do programa na ESF dos municípios, não sendo um critério de atuação do ACS de forma geral ${ }^{22}$. O critério declara que o ACS deve "conhecer na comunidade as condições de vida, hábitos e providências para resolver os problemas, bem o que faz para evitar enfermidades em saúde bucal", este item foi realocado da dimensão "participação da comunidade" para a dimensão "trabalhando educação na saúde da comunidade”. Durante atividades de educação, o ACS deveria interagir com a comunidade na busca por estes dados, de acordo com os princípios da Política de Educação Permanente em Saúde (PNEPS) ${ }^{28}$.

A matriz final deste estudo demonstra a capacidade do ACS de realizar atividades em saúde bucal. O levantamento de dados no cadastramento deve contribuir para o planejamento de ações em conjunto com a ESB. Desta forma, a utilização de indicadores de agravos em saúde bucal neste estudo mostra-se importante. Inquéritos popu- lacionais podem subsidiar esta ação, bem como indicadores existentes em saúde bucal no Contrato Organizativo de Ação Pública em Saúde ${ }^{29}$. Ainda, nesta dimensão de trabalho, a matriz final demonstra a necessidade do ACS estar capacitado em diversos tópicos de saúde bucal, tais como: relação com doenças sistêmicas, câncer de boca e outros fatores de risco com o objetivo de detectar situações que exigem promoção, vigilância e recuperação em saúde bucal. Esta necessidade vem ao encontro de resultados de outros estudos ${ }^{7,30,31}$.

Visitas domiciliares devem identificar novas situações ou grupos de risco e práticas de autocuidado dos pacientes. Este estudo demonstrou que o ACS pode realizar atividades de educação em saúde bucal, desde que seja orientado e não sobreponha ações da equipe auxiliar de saúde bucal. Ainda, procedimentos preventivos também poderiam ser realizados pelo ACS, tanto de forma individual quanto coletiva, ao encontro do preconizado pela $\mathrm{PNAB}^{18,32}$.

Em atividades educativas realizadas pelo ACS, julga-se importante que as mesmas sigam metodologias pré-definidas. O Programa Saúde na Escola (PSE) ${ }^{33}$ e o Caderno de Atenção Básica, $\mathrm{n}^{\mathrm{o}} .17^{15}$, salientam o apoio que o ACS deve prestar em atividades educativas nas escolas, bem como auxiliar no desenvolvimento de ambientes saudáveis, fiscalizando a oferta de alimentos saudáveis e o possível uso de tabaco, álcool e drogas em ambiente escolar.

A participação do ACS na comunidade deve ocorrer através da detecção de dificuldades e estratégias da comunidade para o enfrentamento de problemas em saúde bucal, enfatizando as medidas de solução de problemas, orientação no uso do serviço de saúde bucal da UBS e na promoção e prevenção em saúde bucal conforme critérios de risco $^{34,35}$. Em estudo sobre as percepções dos ACS, estes afirmam que seu objeto de trabalho é a comunidade e seus problemas de saúde. No entanto, a oferta regular de cursos e treinamento para uma formação específica nas áreas em que deveriam atuar é muito irregular, por isso muitos consideram a experiência adquirida com o tempo importante para a realização do trabalho ${ }^{36}$. Conforme Navarro et al. ${ }^{31}$, a implementação de programas de saúde bucal pode estar relacionada com a melhoria da saúde bucal da população. Nesse sentido, a definição das competências do ACS na área da saúde bucal, bem como a qualificação do mesmo através de ações de educação continuada, contribuirá para que esses programas alcancem o objetivo de melhoria da saúde bucal da população ${ }^{37}$. 
Neste estudo, as atribuições em saúde bucal no processo de trabalho do ACS foram construídas mediante publicações oficiais e como consenso de um grupo de especialistas na área pela técnica Delphi, mediante três rodadas. A definição de critérios é uma das formas de definir indicadores de desempenho do processo de trabalho do ACS. Ainda, podem servir como base para políticas de educação permanente na atenção básica. Apesar disso, os ACS possuem outras atribuições e planejamentos, além da saúde bucal no seu processo de trabalho. A aplicação deste estudo na prática exige validação dos seus critérios, assim como novas pesquisas com essa metodologia devam ser realizadas.

Cabe ressaltar que, muitas vezes, os ACS são submetidos a precárias condições de trabalho, reveladas pela baixa remuneração, falta de formação técnica adequada e desvio de suas funções ${ }^{38}$. Estas situações são reflexo de os municípios ainda encontrarem dificuldades para implementar os seus pressupostos, devido à falta de recursos para seu pleno financiamento e indicadores para o processo de trabalho. Novas abordagens e construção de estratégias assistenciais vêm assumir uma relevância ainda maior na implementação do SUS.

Encaminha-se à reflexão sobre a importância do cuidado e planejamento metodológico de pesquisas avaliativas em saúde de forma geral, inclusive no campo dos ACS. Dificuldades são encontradas quanto à disponibilidade na literatura científica de orientação teórica para construção metodológica de estudos avaliativos em saúde que não se restrinjam aos programas e serviços. Estudos futuros precisam incluir a perspectiva do próprio ACS e refinamento das dimensões e critérios, e também das etapas adicionais necessárias para o desenvolvimento de um instrumento de avaliação das ações em saúde bucal sob a responsabilidade dos ACS.

\section{Conclusão}

O estudo permitiu a construção de uma matriz consenso das capacidades de atuação dos ACS em saúde bucal nas UBS e ESF com objetivo de agilizar a ação da ESB na qualificação da atenção a saúde bucal da comunidade.

O instrumento final proposto neste estudo, legitimado pelos diversos atores que compuseram as etapas de construção e validação, representa uma alternativa diferenciada da formação dos ACS, permitindo maior aproximação entre métodos avaliativos da formação em Saúde e realidade da efetivação do processo.

\section{Colaboradores}

AL Sass: desenvolveu a pesquisa, analisou os resultados e redigiu o artigo. FN Hugo: auxiliou na orientação da pesquisa e análise dos resultados. MS Trentin: orientação do trabalho de pesquisa, redação do artigo. AH Silva: revisão do artigo científico. DJ Corralo: auxiliou na redação e revisão do artigo científico. 


\section{Referências}

1. Vasconcelos M, Cardoso AVL, Abreu MHNG. Os desafios dos Agentes Comunitários de Saúde em relação à saúde bucal em município de pequeno porte. Arqu Odontol 2010; 45(2):98-104.

2. Brasil. Lei no 10.507 , de 10 de julho de 2002. Cria a profissão de agente comunitário de saúde e dá outras providências. Diário Oficial da União; 2002.

3. Brasil. Lei no 11.350 , de 5 de outubro de 2006. Regulamenta o $\$ 5^{\circ}$ do art. 198 da Constituição Federal, dispõe sobre o aproveitamento de pessoal amparado pelo parágrafo único do art. $2^{\circ}$ da Emenda Constitucional $\mathrm{n}^{\circ} 51$, de 14 de fevereiro de 2006, e dá outras providências. Diário Oficial da União; 2006.

4. Brasil. Lei no 13.595 , de 5 de janeiro de 2018. Altera a Lei $\mathrm{n}^{\circ} 11.350$, de 5 de outubro de 2006. Diário Oficial da União; 2018.

5. Brasil. Ministério da Saúde (MS). Secretaria de Atenção à Saúde. Departamento de Atenção Básica. Guia prático do agente comunitário de saúde. Brasília: MS; 2009.

6. Brasil. Ministério da Saúde (MS). Secretaria de Atenção à saúde. Departamento de Atenção Básica. O trabalho do agente comunitário de saúde. Brasília: MS; 2009.

7. Holanda ALF, Barbosa AAA, Brito EWG. Reflexões acerca da atuação do agente comunitário de saúde nas ações de saúde bucal. Cien Saude Colet 2009; 14(1):1507-1512.

8. Gouvêa GR, Silva MAV, Pereira AC, Mialhe FL, Cortellazzi KL, Guerra LM. Avaliação do conhecimento em saúde bucal de agentes comunitários de saúde vinculados à Estratégia Saúde da Família. Cien Saude Colet 2015; 20(4):1185-1197.

9. Elias F, Patroclo MAA. Utilização de pesquisas: Como construir modelos teóricos para avaliação? Cien Saude Colet 2004; 10(1):215-227.

10. Balasubramanian D. Delphi technique - A review. Int J Public Health Dent 2012; 3(2):16-25.

11. Ribeiro TR, Pessoa F, Noro LRA. Caminhos para avaliação da formação em Odontologia: Construção de Modelo lógico e validação de critérios. Cien Saude Colet 2015; 20(7):2277-2290.

12. Romeiro C, Nogueira JAPD, Tinoco SG, Carvalho KMB. O modelo lógico como ferramenta de planejamento, implantação e avaliação do Programa de Promoção de Saúde na Estratégia de Saúde da Família do Distrito Federal. Rev Bras Ativ Física Saúde 2013; 18(1):132-142.

13. Okoli C, Pawlowski SD. The Delphi method as a research tool: an example, design, considerations and application. Information Management 2004; 42:15-29.

14. FormSus ${ }^{\circledR}$-Versão 3.0. DATASUS [Internet]. [acessado 2013 Nov 10]. Disponível em: http://formsus.datasus.gov.br/ site/default.php

15. Souza LEPF, Silva LMV, Hartz ZMA. Conferência de Consenso sobre a imagem-objetivo da descentralização da atenção à saúde bucal. In: Hartz, ZMA, Silva LMV. Avaliação em Saúde dos modelos teóricos à prática na avaliação de programas e sistemas de saúde. Salvador: EDUFBA; 2000. p. 65-103.
16. Ashton CM, Kuykendall DH, Johnson ML, Wun CC, Wray MJ, Slater CH, Wu L, Bush GRW. A method of developing and weighting explicit process of care criteria for Quality Assessment. Med Care 1994; 32(8):755-770.

17. Maciazeki-Gomes RC, Souza CD, Baggio L, Wachs F. O trabalho do agente comunitário de saúde na perspectiva da educação popular em saúde: possibilidades e desafios. Cien Saude Colet 2016; 21(5):1637-1646.

18. Brasil. Portaria no 2.436, de 21 de setembro de 2017. Aprova a Política Nacional de Atenção Básica, estabelecendo a revisão de diretrizes para a organização da Atenção Básica, no âmbito do Sistema Único de Saúde (SUS). Diário Oficial da União; 2017.

19. Pereira HS, Limongi JE. Agentes Comunitários de Saúde: Atribuições e Desafios. Hygeia 2011; 7(12):8389.

20. Nascimento CMB. Precarização do trabalho do Agente Comunitário de Saúde: um estudo em municípios da região metropolitana do Recife [Internet]. 2005 [acessado 2010 Jul 8]. Disponível em www.cpcam.fiocruz.br

21. Brasil. Lei no 8.080, de 19 de setembro de 1990. Dispõe sobre as condições para promoção, proteção e recuperação da saúde, a organização e o funcionamento dos serviços correspondentes e dá outras providências. Diário Oficial da União; 1990.

22. Costa SM, Araújo FF, Martins LV, Nobre LLR, Araújo FM, Rodrigues CAQ. Agente Comunitário de Saúde: elemento nuclear das ações em saúde. Cien Saude Colet $2013 ; 18(7): 2147-2156$.

23. Brasil. Lei no 8.142 , de 28 de dezembro de 1990. Dispõe sobre a participação da comunidade na gestão do Sistema Único de Saúde (SUS) e sobre as transferências intergovernamentais de recursos financeiros na área da saúde e dá outras providências. Diário Oficial da União, 1990.

24. Brasil. Ministério da Saúde (MS). Secretaria Executiva Programa agentes comunitários de saúde (PACS). Brasília: MS; 2001.

25. Valdés MG, Marín MS. Empleo del método Delphi en investigaciones sobre salud publicadas en revistas científicas cubanas. Rev Cubana Información Ciencias Salud 2013; 24(2):133-144.

26. Bloor M, Sampson H, Baker S, Dahlgren K. Useful but no Oracle: Reflections on the use of a Delphi Group in a multi-methods policy research study. Quali Res 2014; 15(1):57-70.

27. Brasil. Ministério da Saúde (MS). Secretaria de Atenção à Saúde. Departamento de Atenção Básica. Política Nacional de Práticas Integrativas e Complementares no SUS-PNPIC-SUS. Brasília: MS; 2006.

28. Brasil. Ministério da Saúde (MS). Gabinete do Ministro. Portaria no 2.761, de 19 de novembro de 2013. Política Nacional de Educação Popular em Saúde no âmbito do Sistema Único de Saúde (PNEPS-SUS). Diário Oficial da União; 2013.

29. Brasil. Ministério da Saúde (MS). Decreto no 7.508, de 28 de junho de 2011. Regulamenta a Lei no 8.080 de 19 de setembro de 1990. Diário Oficial da União; 2011. 
30. Frazão P, Marques D. Influência de Agentes Comunitários de Saúde na percepção de mulheres e mães sobre conhecimentos de saúde bucal. Rev Saúde Pública 2009; 43(3):463-471.

31. Navarro MFL, Modena KCS, Bresciani E. Social disparity and oral health. Brazil Oral Res 2012; 26(1):17-24.

32. Brasil. Ministério da Saúde (MS). Resolução no 333, de 4 de novembro de 2003. Aprova as diretrizes para criação, reformulação, estruturação e funcionamento dos Conselhos de Saúde. Diário Oficial da União; 2003.

33. Brasil. Ministério da Saúde (MS). Secretaria de Atenção à Saúde. Departamento de Atenção Básica. Saúde na Escola. Brasília: MS; 2009.

34. Moretti AC, Teixeira FF, Sus FMB, Lawder JAC, Lima LSM, Bueno RE, Moysés SJ. Intersetorialidade nas ações de promoção de saúde realizadas pelas equipes de saúde bucal de Curitiba (PR). Cien Saude Colet 2010; 15(1):1827-1834.

35. Scherer MDA, Pires DEP, Jean R. A construção da interdisciplinaridade no trabalho da Equipe de Saúde da Família. Cien Saude Colet 2013; 18(11):3203-3212.

36. Filgueiras AS, Silva ALA. Agente Comunitário de Saúde: um novo ator no cenário da saúde do Brasil. Physis 2011; 21(3):899-915.

37. Brasil. Ministério da Saúde (MS). Secretaria de Atenção à Saúde. Secretaria de Vigilância em Saúde. $S B$ Brasil 2010: Pesquisa Nacional de Saúde Bucal: resultados principais. Brasília: MS, 2012.

38. Carneiro CCG, Martins MIC. Novos modelos de gestão do trabalho no setor público de saúde e o trabalho do Agente Comunitário de Saúde. Rev Trabalho Educ Saúde 2015; 13(1):45-46.

Artigo apresentado em 24/02/2019

Aprovado em 07/05/2019

Versão final apresentada em 09/05/2019

Editores-chefes: Romeu Gomes, Antônio Augusto Moura da Silva 
